\title{
Once-daily indacaterol versus twice-daily salmeterol for COPD: a placebo-controlled
} comparison

\author{
O. Kornmann*, R. Dahl" ${ }^{\#}$ S. Centanni", A. Dogra ${ }^{+}$, R. Owen ${ }^{\S}$, C. Lassen ${ }^{\S}$ and \\ B. Kramer ${ }^{+}$, on behalf of the INLIGHT-2 (Indacaterol Efficacy Evaluation Using \\ 150- $\mu$ g Doses with COPD Patients) study investigators
}

ABSTRACT: Indacaterol is a novel, inhaled, once-daily, ultra-long-acting $\boldsymbol{\beta}_{2}$-agonist bronchodilator recently approved in Europe for the treatment of chronic obstructive pulmonary disease (COPD). The aim of the present study was to investigate the efficacy and safety of indacaterol compared with placebo and the twice-daily $\beta_{2}$-agonist, salmeterol, as an active control.

Patients with moderate-to-severe COPD were randomised to 6 months double-blind treatment with indacaterol (150 $\mu \mathrm{g}$ once daily), salmeterol (50 $\mu \mathrm{g}$ twice daily) or placebo. The primary efficacy end-point was trough ( $24 \mathrm{~h}$ post-dose) forced expiratory volume in $1 \mathrm{~s}$ (FEV 1 ) after 12 weeks.

1,002 patients were randomised and $838(84 \%)$ completed the study. Indacaterol increased trough FEV 1 at week 12 by $170 \mathrm{~mL}$ over placebo $(p<0.001)$ and by $60 \mathrm{~mL}$ over salmeterol $(p<0.001)$. Both active treatments improved health status (St George's Respiratory Questionnaire) and dyspnoea (transition dyspnoea index) compared with placebo, with differences between them favouring indacaterol. Safety profiles were similar across the treatment groups, and both indacaterol and salmeterol were well tolerated.

Once-daily treatment with $150 \mu \mathrm{g}$ indacaterol had a significant and clinically relevant bronchodilator effect over $24 \mathrm{~h}$ post-dose and improved health status and dyspnoea to a greater extent than twice-daily $\mathbf{5 0} \mu \mathrm{g}$ salmeterol. Indacaterol should prove a useful additional treatment for patients with COPD.

KEYWORDS: Bronchodilator, chronic obstructive pulmonary disease, clinical trial, indacaterol, salmeterol

hronic obstructive pulmonary disease (COPD) is estimated to affect $10 \%$ of the world's population aged $\geqslant 40 \mathrm{yrs}$, and prevalence is expected to continue to increase over coming years [1, 2]. Regular treatment with one or more long-acting inhaled bronchodilators is an important and recommended element in managing the symptoms of patients with COPD [3]. These agents are administered twice daily (the $\beta_{2}$-agonists formoterol and salmeterol) or once daily (the anticholinergic tiotropium). Indacaterol is an inhaled ultra-long-acting $\beta_{2}$-agonist bronchodilator that has demonstrated 24-h efficacy on once-daily administration, and was recently approved in the EU at two doses, 150 and $300 \mu \mathrm{g}$ once daily, for use in the maintenance treatment of patients with COPD.

In deciding whether to use a new agent, it is clearly useful to know how the efficacy and safety of indacaterol compare with other longacting bronchodilators using studies of suitable design and appropriate duration. The present study is one of a series designed to compare indacaterol with currently available long-acting bronchodilators. The other studies were a 6month comparison of indacaterol (150 and $300 \mu \mathrm{g})$ with tiotropium [4] and a 1-yr comparison of indacaterol $(300 \mu \mathrm{g})$ with formoterol [5]. The present study compares indacaterol $(150 \mu \mathrm{g}$ once daily) with salmeterol (50 $\mu$ g twice daily) over 6 months.

\section{METHODS}

The study was approved by the ethics committees or institutional review boards of participating centres and was conducted in respiratory outpatient clinics, physicians' offices and clinical research centres.
AFFILIATIONS

*Pulmonary Division, Internal Medicine, University Hospital, Mainz, Germany.

"Dept of Respiratory Diseases, Aarhus University Hospital, Aarhus, Denmark.

"Unità Operativa di Pneumologia, Ospedale S. Paolo, Università degli Studi di Milano, Milan, Italy.

${ }^{+}$Respiratory Development, Novartis Pharmaceuticals Corporation, East Hanover, NJ, USA.

${ }^{\S}$ Novartis Horsham Research Centre, Wimblehurst Road, Horsham, UK.

\section{CORRESPONDENCE}

O. Kornmann

IKF Pneumologie GmbH \& Co. KG Clinical Research Centre Respiratory Diseases

Am Standort IFS

Stresemannallee 3

60596 Frankfurt

Germany

E-mail: kornmann@

ikf-pneumologie.de

Received:

March 232010

Accepted after revision:

July 092010

First published online:

Aug 062010 


\section{Patients}

Males and females aged $\geqslant 40$ yrs with a clinical diagnosis of moderate-to-severe COPD [6] and a smoking history of $\geqslant 20$ pack-yrs were enrolled in the study. Spirometry test results at screening were forced expiratory volume in $1 \mathrm{~s}$ (FEV1) $<80 \%$ predicted and $\geqslant 30 \%$ predicted, and FEV1/ forced vital capacity $<0.7$, measured within $30 \mathrm{~min}$ of inhaling $400 \mu \mathrm{g}$ salbutamol. Patients with a history of asthma were excluded. All patients gave written, informed consent.

\section{Study design}

Following a 2-week run-in and screening period, during which baseline variables were assessed and concomitant medication stabilised, patients were randomised to receive double-blind treatment with indacaterol $(150 \mu \mathrm{g}$ once daily via single-dose dry-powder inhaler, taken in the morning), salmeterol (50 $\mu \mathrm{g}$ twice daily (morning and evening) via its proprietary drypowder inhaler) or placebo for 26 weeks. Placebos matching both active treatments were used to maintain blinding.

Patients were permitted concomitant medication with inhaled corticosteroids (ICS), if dose and regimen were stable for 1 month prior to screening. Dose and regimen remained stable throughout the study. Patients previously on fixed combinations of ICS and long-acting $\beta_{2}$-agonist were switched to the equivalent ICS monotherapy, at a dose and regimen that was maintained throughout the study. Salbutamol was provided for use as needed (but not $<6 \mathrm{~h}$ before study assessments).

\section{Objectives, assessments and outcome measures}

The primary objective was to confirm the superiority of $150 \mu \mathrm{g}$ indacaterol over placebo with respect to 24-h post-dose "trough" FEV1 after 12 weeks. Trough FEV1 was defined as the average of the values at $23 \mathrm{~h} 10 \mathrm{~min}$ and $23 \mathrm{~h} 45 \mathrm{~min}$ following the previous day's morning dose, and was also determined on day 2 and week 26. Spirometry was also performed at intervals up to $1 \mathrm{~h}$ post-dose at each clinic visit. Secondary objectives were to compare the effect of indacaterol versus salmeterol and salmeterol versus placebo on trough FEV1 at week 12, and to evaluate the effect of treatment (all comparisons) on FEV1 at other time points, on other efficacy outcomes (health status, diary assessments and dyspnoea) and on safety and tolerability.

Health status was assessed by St George's Respiratory Questionnaire (SGRQ) [7], which patients completed at baseline, and at weeks 4, 8, 12 and 26. The minimum clinically important difference (MCID) was four points in SGRQ total score [8]. Dyspnoea was assessed at baseline as the baseline dyspnoea index, and at weeks 4, 8, 12 and 26 as the transition dyspnoea index (TDI) [9], with a change of one point regarded as the MCID [10]. Patients recorded their symptoms, pretreatment peak expiratory flow (PEF) morning and evening, and use of as-needed salbutamol in an electronic diary, completed daily. A composite measure of "days of poor COPD control" was based on an end-point used in formoterol registration studies [11, 12], and was defined as days with a score $\geqslant 2$ on a $0-3$ scale for at least two symptoms out of cough, wheeze, production/colour of sputum and breathlessness. The effect of indacaterol relative to placebo on SGRQ score at week 12 and on percentage days of poor COPD control were predefined important secondary end-points.
At each clinic visit, adverse events were recorded, vital signs were monitored and ECGs recorded. The QT interval was calculated using Fridericia's correction. Blood samples were taken at each visit pre- and $1 \mathrm{~h}$ post-dose for haematology and blood chemistry. Clinically notable laboratory values were specified for reduced serum potassium $\left(<3.0 \mathrm{mmol} \cdot \mathrm{L}^{-1}\right)$ and elevated blood glucose $\left(>9.99 \mathrm{mmol} \cdot \mathrm{L}^{-1}\right)$. Investigators were asked to record any events they observed within 5 min of drug administration at clinic visits, including cough (as distinct from reports of cough as an adverse event).

\section{Statistical methods}

Patients were randomly allocated to treatment in a 1:1:1 ratio (with stratification for smoking status) using an automated system. Blinding was maintained from randomisation until database lock unless any patient emergencies arose.

Efficacy variables were analysed using a mixed-model ANCOVA, including treatment as a fixed effect, with the appropriate baseline measurement, and baseline FEV1 reversibility as covariates, smoking status and country as fixed effects, and centre nested within country as a random effect. Owing to the issue of multiplicity, the primary and important secondary efficacy variables were analysed in a hierarchical fashion, i.e. the primary efficacy variable, then SGRQ total score at 12 weeks, then percentage of days of poor COPD control (all for superiority of indacaterol versus placebo). Other efficacy variables and treatment comparisons were analysed without allowance for multiplicity. Results of the ANCOVA are expressed as (adjusted) least squares means with associated $95 \%$ confidence intervals for the treatment contrasts. Raw mean (nonadjusted) data are also presented for the changes from baseline in TDI and SGRQ scores.

Efficacy data were analysed for the intention-to-treat (ITT) population, comprising all randomised patients who received at least one dose of the study drug. The population for the safety analysis comprised all patients who received at least one dose of the study drug.

\section{Sample size determination}

A treatment difference between indacaterol and placebo of $120 \mathrm{~mL}$ in trough FEV1 was pre-specified as a clinically important difference for COPD patients. Based on this, and a standard deviation of $270 \mathrm{~mL}$ for trough FEV1 based on previous data [11, 12], a sample size of 108 evaluable patients in each treatment group was needed to detect this difference as statistically significant at the 5\% significance level (two-sided) with $90 \%$ power. The criterion for the sample size decision also targeted $90 \%$ power for the symptomatic end-point, percentage of COPD days of poor control, which (assuming a standard deviation of $28 \%$ [11, 12]) required 259 evaluable patients per treatment group to detect an $8 \%$ difference as statistically significant at the $5 \%$ significance level (two-sided). This, being the larger number, defined the sample size. Assuming a $15 \%$ drop-out over the first 12 weeks of treatment, the resulting target sample size of 324 patients per treatment group would provide $>99 \%$ power for the primary end-point.

\section{RESULTS}

The study involved 142 centres in 15 countries, and patients were treated between November 2007 and January 2009. Of 
TABLE 1 Disposition of patients during the study

\begin{tabular}{|c|c|c|c|}
\hline Randomised & $333(100.0)$ & $334(100.0)$ & $335(100.0)$ \\
\hline Completed & $289(86.8)$ & $284(85.0)$ & 265 (79.1) \\
\hline Discontinued & $44(13.2)$ & $50(15.0)$ & $70(20.9)$ \\
\hline \multicolumn{4}{|c|}{ Primary reason for premature discontinuation } \\
\hline Subject withdrew consent & $8(2.4)$ & $12(3.6)$ & $22(6.6)$ \\
\hline Abnormal lab value(s) & $2(0.6)$ & $1(0.3)$ & $2(0.6)$ \\
\hline Abnormal test procedure result(s) & $2(0.6)$ & $1(0.3)$ & $1(0.3)$ \\
\hline Lost to follow-up & $2(0.6)$ & $5(1.5)$ & $2(0.6)$ \\
\hline Unsatisfactory therapeutic effect & $1(0.3)$ & $2(0.6)$ & $15(4.5)$ \\
\hline Safety population & $330(99.1)$ & $333(99.7)$ & $335(100.0)$ \\
\hline
\end{tabular}

1,518 patients screened, 1,002 were randomised, of whom 838 $(84 \%)$ completed the study. Discontinuations were more common from the placebo arm, owing mainly to lack of therapeutic effect and withdrawal of consent (table 1). Table 2 shows demographic data and disease characteristics for the treated patients.

\section{Spirometry}

Figure 1 shows the differences between active treatments and placebo for trough FEV1 at day 2, week 12 and week 26.
Differences versus placebo were significant for both indacaterol and salmeterol at all assessments $(\mathrm{p}<0.001)$, with trough FEV1 significantly greater with indacaterol than with salmeterol at weeks 12 and 26 (by $60 \mathrm{~mL}$ and $70 \mathrm{~mL}$; both $\mathrm{p}<0.001$ ). As changes from baseline, trough FEV1 at week 12 increased by $150 \mathrm{~mL}(13 \%)$ with indacaterol and by $90 \mathrm{~mL}(8 \%)$ with salmeterol, and decreased by $30 \mathrm{~mL}(0.7 \%)$ with placebo. Indacaterol maintained a clinically significant increase over placebo during the course of the study, with an increase from $130 \mathrm{~mL}$ at $24 \mathrm{~h}$ following the first dose to $170 \mathrm{~mL}$ at week 12

TABLE 2 Demographics and baseline characteristics

\begin{tabular}{|c|c|c|c|}
\hline Subjects $\mathrm{n}$ & 330 & 333 & 335 \\
\hline Males/females \% & $72 / 28$ & $75 / 25$ & $77 / 23$ \\
\hline Duration of COPD yrs & $6.5 \pm 5.7$ & $6.4 \pm 5.7$ & $6.6 \pm 5.8$ \\
\hline Ex-smokers/smokers \% & $54 / 46$ & $54 / 46$ & $55 / 45$ \\
\hline $\mathrm{FEV}_{1}{ }^{\#} \mathrm{~L}$ & $1.5 \pm 0.49$ & $1.5 \pm 0.49$ & $1.5 \pm 0.47$ \\
\hline $\mathrm{FEV}_{1} \# \%$ pred & $54 \pm 14.0$ & $53 \pm 13.6$ & $53 \pm 14.2$ \\
\hline $\mathrm{FEV}_{1} / \mathrm{FVC}^{\#}$ & $0.5 \pm 0.10$ & $0.5 \pm 0.10$ & $0.5 \pm 0.11$ \\
\hline Reversibility to salbutamol \% & $12 \pm 15.3$ & $11 \pm 13.9$ & $13 \pm 16.4$ \\
\hline SGRQ total score & $43 \pm 18.6$ & $44 \pm 18.4$ & $44 \pm 18.1$ \\
\hline
\end{tabular}

Data are presented as mean \pm SD, unless otherwise stated. COPD: chronic obstructive pulmonary disease; ICS: inhaled corticosteroid; FEV1: forced expiratory volume in $1 \mathrm{~s}$; \% pred: \% predicted; FVC: forced vital capacity; SGRQ: St George's Respiratory Questionnaire; BDI: baseline dyspnoea index. " ${ }^{*}$ post-salbutamol. 


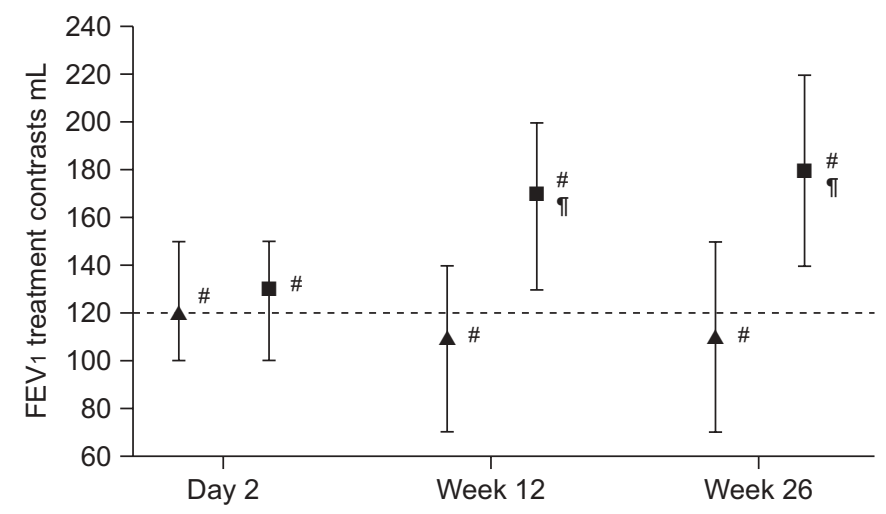

FIGURE 1. Differences between active treatments ( $\mathbf{\Delta}$ : salmeterol; indacaterol) over placebo for trough forced expiratory volume in $1 \mathrm{~s}$ (FEV1). Data are presented as least squares means and whiskers represent $95 \% \mathrm{Cl}$. Patient numbers analysed at day 2, week 12 (primary end-point) and week 26, respectively, were 317, 320 and 300 (indacaterol), 320, 317 and 291 (salmeterol), and 321, 316 and 274 (placebo). ---: pre-specified $120 \mathrm{~mL}$ clinically important difference versus placebo. ${ }^{*}: p<0.001$ versus placebo; ${ }^{\uparrow}: p<0.001$ for indacaterol versus salmeterol.

and $180 \mathrm{~mL}$ at week 26; the salmeterol-placebo difference was smaller and did not increase with length of treatment (120, 110 and $110 \mathrm{~mL}$ at day 2, week 12 and week 26, respectively).

5 min after the first dose on day 1, FEV1 increased over placebo by $110 \mathrm{~mL}(95 \%$ CI $90-130 \mathrm{~mL}$ ) with indacaterol and by $60 \mathrm{~mL}$ (95\% CI 40-80 mL) with salmeterol $(\mathrm{p}<0.001$ for both versus placebo), with an advantage for indacaterol over salmeterol of $50 \mathrm{~mL} \quad(95 \%$ CI 30, $70 \mathrm{~mL}$; $\mathrm{p}<0.001)$. An advantage of $60-100 \mathrm{~mL}$ for indacaterol over salmeterol $(\mathrm{p}<0.01)$ at the $5 \mathrm{~min}$ after dose time-point was observed at all remaining clinic visits.

Health status, symptoms and use of as-needed salbutamol The unadjusted mean SGRQ total score with indacaterol decreased (i.e. improved health status) from baseline by more than the four-point minimum clinically important difference at all visits (fig. 2). The adjusted mean SGRQ total score was significantly lower than placebo with indacaterol (differences of $-3.6,-4.1,-6.3$ and -5.0 at weeks $4,8,12$ and 26 ; all $\mathrm{p}<0.001$ ) and salmeterol (-2.5, -3.6, -4.2 and -4.1 at weeks $4,8,12$ and 26; all $\mathrm{p}<0.01)$ throughout the study. The difference between indacaterol and salmeterol was significant $(p<0.05)$ at week 12 , the specified time-point for SGRQ as an important secondary variable.

The percentages of patients with a clinically important improvement from baseline SGRQ total score of $\geqslant 4$ units, and the odds ratios versus placebo for the likelihood of achieving this improvement, are shown in table 3. The difference between indacaterol and salmeterol was significant at week 12 (OR 1.59, 95\% CI 1.12-2.25; p<0.01).

The mean \pm SE percentage of days of poor COPD control over 26 weeks was $34.1 \pm 1.82 \%$ with both indacaterol and salmeterol, compared with $38.1 \pm 1.85 \%$ with placebo; the reductions from placebo were not statistically significant either for indacaterol $(-4.0 \%, 95 \%$ CI $-8.0-0.1 \%$; $\mathrm{p}=0.058)$ or salmeterol $(-4.0 \%, 95 \%$ CI $-8.1-0.1 ; \mathrm{p}=0.057)$. Compared with salmeterol, indacaterol-treated patients used less as-needed salbutamol, had higher morning PEF and experienced more days when

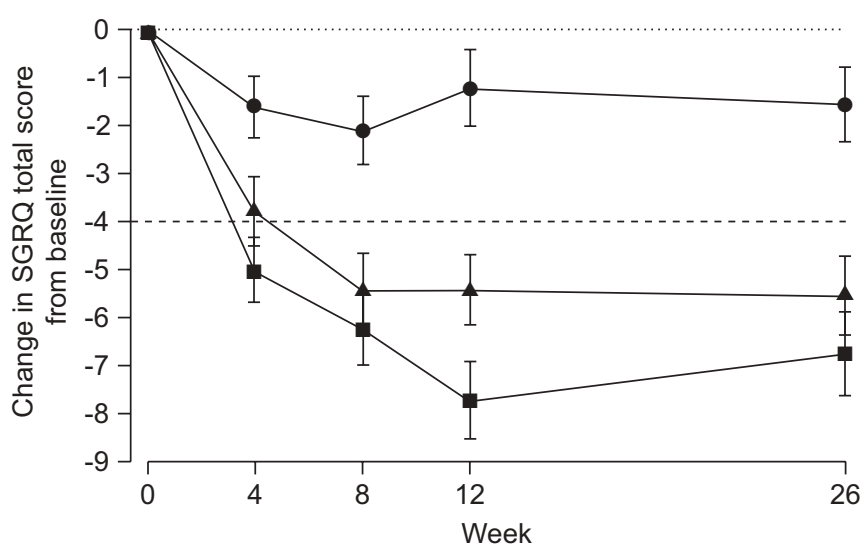

FIGURE 2. Changes from baseline in St George's Respiratory Questionnaire (SGRQ) total score. Data are presented as unadjusted mean \pm SE. Patient numbers analysed at weeks 4, 8, 12 and 26 were, respectively, 311, 304, 309 and 299 (indacaterol; $\boldsymbol{- 1}$ ), 302, 300, 301 and 292 (salmeterol; $\mathbf{\Delta}$ ), and 298, 294, 294 and 274 (placebo; -). ---: clinically important change. Note that a downward shift of the curve indicates improvement on this graph.

they were able to undertake usual activities (table 4). Figure 3 shows the unadjusted mean change from baseline in TDI total score at weeks 4, 8, 12 and 26. Adjusted mean total score was higher than placebo with both salmeterol $(p<0.05)$ and indacaterol $(p<0.001)$ at all visits. The mean differences versus placebo were numerically larger with indacaterol than with salmeterol, significantly so at weeks 4 ( 0.95 versus $0.55 ; \mathrm{p}<0.05)$ and 12 (1.45 versus $0.90 ; \mathrm{p}<0.05)$. The percentage of patients with clinically important improvements in TDI total score of $\geqslant 1$ unit at weeks $4,8,12$ and 26 were $39.5-45.7 \%$ with placebo, $48.7-53.6 \%$ with salmeterol and $56.6-60.5 \%$ with indacaterol. Odds ratios for the likelihood of achieving this improvement were significant for indacaterol over placebo at each time point $(2.26,1.71,2.79$ and 1.87 at weeks 4, 8, 12 and 26, respectively; all $\mathrm{p}<0.001$ ), while the odds ratio for salmeterol versus placebo was significant only at weeks 12 and 26 (2.13 and 1.90; $\mathrm{p} \leqslant 0.001)$.

\section{Safety}

Table 5 shows the overall incidence of adverse events and those reported most frequently. Those events that might be considered to be typically $\beta_{2}$-adrenoceptor-mediated were rarely reported (tremor, one patient in each of the indacaterol and salmeterol groups; tachycardia, one patient treated with indacaterol). The proportions of patients with serious adverse events were similar across the groups: $7.8,5.7$ and $8.8 \%$, for placebo, salmeterol and indacaterol, respectively. Among these, the most commonly affected categories were "respiratory, thoracic and mediastinal" (including COPD worsening) and "infections and infestations" (including respiratory tract infections). The incidence of bacterial and viral upper respiratory tract infections as adverse events was higher with indacaterol, although most cases (23 out of 24 ) were mild or moderate.

Four deaths occurred, three during treatment and one during the 30-day follow-up period. None was considered to be related to treatment. The deaths occurred in one patient in the indacaterol group (cardiac arrest) and three in the placebo 
TABLE 3 Health status responder analysis

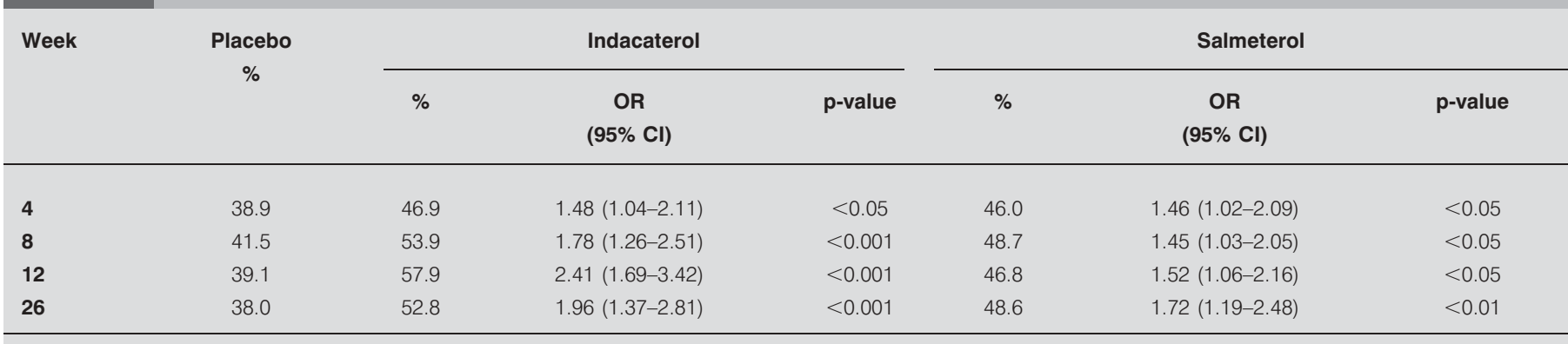

Percentage of patients achieving minimal clinically important differences (MCID) in St George's Respiratory Questionnaire score ( $\geqslant 4$-point increase), and odds ratios and $\mathrm{p}$-values versus placebo for likelihood of achieving the MCID.

group (cardiorespiratory arrest, multiorgan failure and COPD exacerbation).

Clinically notable values for blood glucose $\left(>9.99 \mathrm{mmol} \cdot \mathrm{L}^{-1}\right)$ were recorded for $5.8 \%$ of indacaterol-treated patients, $9.0 \%$ of salmeterol-treated patients and $6.3 \%$ of the placebo group. Clinically notable serum potassium values of $<3.0 \mathrm{mmol} \cdot \mathrm{L}^{-1}$ were recorded for $0.3 \%, 0.6 \%$ and $0 \%$ of the indacaterol, salmeterol and placebo groups, respectively.

QTc interval increases from baseline of $>60$ ms were recorded for two patients, one each in the indacaterol and salmeterol groups. The indacaterol patient with the $>60 \mathrm{~ms}$ increase also had a notable high value $(557 \mathrm{~ms})$ at the time. His baseline value was at the higher end of normal $(433 \mathrm{~ms})$ and he had a number of medical problems that became apparent during the study (jaundice, adenocarcinoma and alcoholism).

As an adverse event, cough was reported by $2.4 \%$ of indacaterol-treated patients, similar to the $2.7 \%$ of salmeterol patients and lower than the $3.9 \%$ of placebo patients. In contrast, investigators observed cough following inhalation of study drug in an average of $17.6 \%$ (indacaterol), $0.9 \%$ (salmeterol) and $2.5 \%$ (placebo) of patients per visit. In the majority of cases, this cough started within $15 \mathrm{~s}$ of inhalation and had a median duration of $12 \mathrm{~s}$. The cough was not associated with bronchospasm, increased study discontinuation rates, or loss of bronchodilator efficacy. Only two patients withdrew from the study because of cough, neither of whom was receiving indacaterol.

\section{DISCUSSION}

Similar to the way in which the twice-daily $\beta_{2}$-agonist bronchodilators were shown to be more effective treatments for COPD patients than more frequently dosed short-acting bronchodilators $[5,13]$, in this 6-month comparison, a oncedaily $\beta_{2}$-agonist was generally more effective than a twicedaily agent. Comparing the bronchodilator effect $24 \mathrm{~h}$ after the dose of indacaterol and $12 \mathrm{~h}$ after the previous evening's dose of salmeterol, trough FEV1 was significantly higher with indacaterol than with salmeterol at all visits during the 6month period. The difference in trough effect with indacaterol of $170-180 \mathrm{~mL}$ relative to placebo after 12 and 26 weeks exceeded the pre-specified $120 \mathrm{~mL}$ clinically important activeplacebo difference (a value at the mid-point of the range accepted as clinically important [14]), and there was no loss of bronchodilator effect over the course of the study. Salmeterol had a smaller effect at these times and did not achieve the $120 \mathrm{~mL}$ trough FEV1 threshold for a difference versus placebo.

The effect of salmeterol on trough FEV1 was similar to that observed in other studies [15-17]. The additional efficacy of

TABLE 4 Symptom-related outcomes and peak expiratory flow (PEF) over 26 weeks

\begin{tabular}{|c|c|c|c|}
\hline & Placebo & Indacaterol & Salmeterol \\
\hline Change from baseline in as-needed salbutamol use puffs day ${ }^{-1}$ & $-0.3 \pm 0.16$ & $-1.3 \pm 0.16^{\#}$ & $-1.2 \pm 0.16^{\#}$ \\
\hline Days with no as-needed salbutamol use $\%$ & $42.2 \pm 2.59$ & $59.7 \pm 2.58^{\#, \bullet}$ & $54.7 \pm 2.58^{\#}$ \\
\hline Change from baseline in morning PEF L. $\mathrm{min}^{-1}$ & $-0.8 \pm 2.74$ & $25.3 \pm 2.72^{\#,+}$ & $15.2 \pm 2.73^{\#}$ \\
\hline Change from baseline in evening PEF L. $\mathrm{min}^{-1}$ & $-2.3 \pm 2.82$ & $23.4 \pm 2.80^{\#,+}$ & $12.7 \pm 2.80^{\#}$ \\
\hline Nights with no awakenings \% & $65.3 \pm 1.64$ & $71.6 \pm 1.61^{\#}$ & $70.8 \pm 1.62^{\S}$ \\
\hline
\end{tabular}

Data are presented as least squares mean \pm SE. Patient numbers evaluated for the different outcomes were 301-304 for placebo, 306-310 for indacaterol and 303-310 for salmeterol. ${ }^{\#}: \mathrm{p}<0.001$ versus placebo; ${ }^{\natural}: \mathrm{p}<0.05$ versus salmeterol; ${ }^{+}: \mathrm{p}<0.001$ versus salmeterol; ${ }^{\text {s. }} \mathrm{p}<0.01$ versus placebo; ${ }^{\text {f: }} \mathrm{p}<0.05$ versus placebo. 


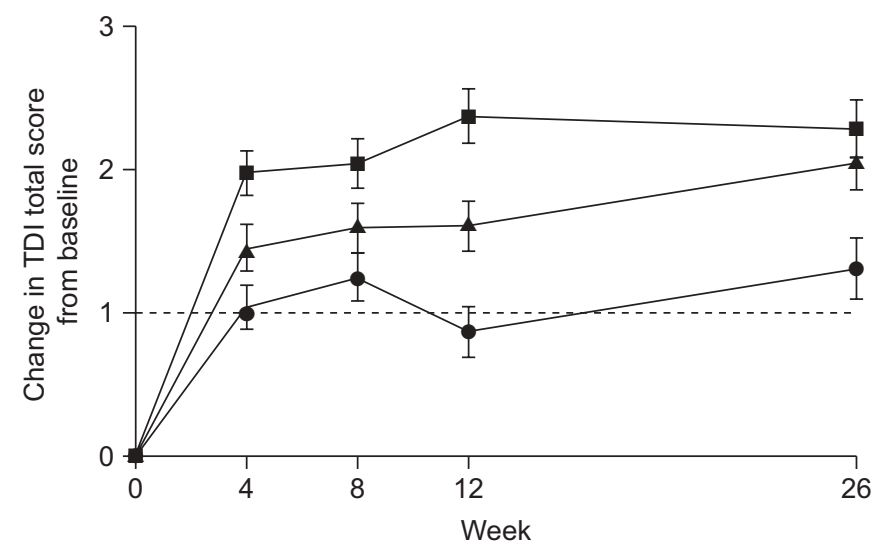

FIGURE 3. Changes from baseline in transition dyspnoea index (TDI) total score. Data are presented as unadjusted mean \pm SE. Patient numbers analysed at weeks 4, 8, 12 and 26 were, respectively, 309, 300, 303 and 297 (indacaterol; 口), 298, 292, 296 and 289 (salmeterol; $\mathbf{\Delta}$ ), and 295, 282, 286 and 272 (placebo; $\bullet$ ). ---: clinically important change.

50-60 mL provided by indacaterol over salmeterol is similar to the margin provided by once-daily tiotropium over salmeterol [15]. The choice of trough FEV1 as a primary end-point is relevant to COPD patients, given that the early morning is when COPD patients report symptoms to be at their worst and when they have difficulty accomplishing activities [18]. Morning PEF was also higher with indacaterol compared with salmeterol. The additional improvement in airflow with indacaterol at this time, both before and just after dosing, may help patients start to undertake their morning activities. The effects of indacaterol monotherapy on morning lung function appear similar to previous findings with combined bronchodilator treatment [19].

Across the range of outcomes evaluated, once-daily $150 \mu \mathrm{g}$ indacaterol was more effective than placebo and, in most cases, more effective than twice-daily salmeterol. Indacaterol-treated patients reported improved health status (as measured by SGRQ) relative to placebo, by a margin that was close to (week 4) or exceeded (weeks 8-26) the MCID for this measure. Salmeterol had a lesser, but still significant, effect. The effect of indacaterol and salmeterol on dyspnoea followed a pattern similar to that of the health status results. Both treatments were more effective than placebo, with indacaterol reaching statistical significance versus salmeterol at weeks 4 and 12. This was observed even though salmeterol had a larger effect on dyspnoea [13, 15, 16, 20] and health status [15, 21] than in previous studies. Reasons for the differences are unclear and do not appear to be due to differences in COPD severity. The effects of indacaterol on these end-points were consistent with those seen at the 6-month time point in other studies [4, 5]. Breathlessness is considered the most disabling symptom for the COPD patient [22], and a sustained reduction in dyspnoea is an important finding for indacaterol. Indacaterol also allowed patients more days without recourse to salbutamol use and they were better able to undertake usual activities, compared with salmeterol.

FEV1 was chosen as the primary end-point in order to meet regulatory requirements for a clinical study aimed to support

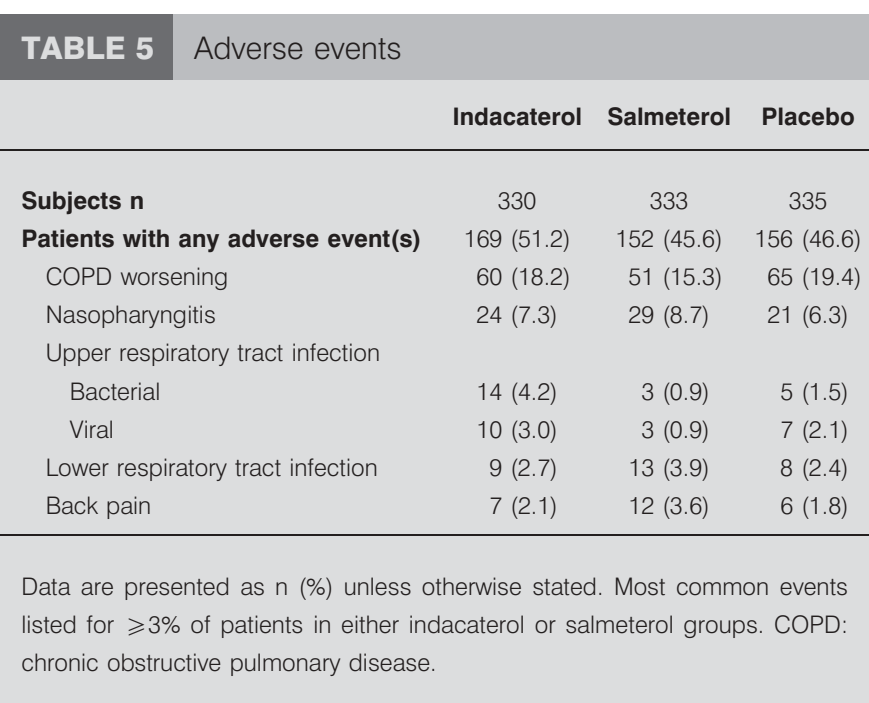

registration of a bronchodilator treatment for COPD. The timing of the primary end-point (12 weeks) also reflected regulatory standards. It may be more relevant to everyday clinical practice to focus on a clinical outcome such as dyspnoea, and the focus on FEV1 may have reduced the power to investigate the effect of indacaterol on those other end-points. The study was not sufficiently powered to detect the small reductions in "days of poor COPD control" that occurred with indacaterol and salmeterol as statistically significant versus placebo. This instrument, although used previously [11, 12], has not been validated, and relies on accurate completion of daily diaries. However, the other key secondary variable, SGRQ total score, was robust in showing a marked treatment effect.

Safety and tolerability were similar across the treatment groups, and the greater efficacy and duration of bronchodilator effect of indacaterol was not reflected in any increase in $\beta_{2}$-mediated effects relative to salmeterol. Similar observations were made in a 1-yr study employing higher doses (300 and $600 \mu \mathrm{g})$ of indacaterol [5]. Although bacterial and viral upper respitatory tract infection (URTI) were more frequent with indacaterol treatment, other similar adverse events (e.g. URTI and rhinitis) occurred more frequently with placebo. In the 1-yr study of indacaterol 300 and $600 \mu \mathrm{g}$ [5], bacterial URTI was observed in $\sim 6 \%$ of patients in both indacaterol groups, compared with $8 \%$ in the placebo group. In the present study, the event rate per patient-yr for the overall category "infections and infestations" was less than one in all treatment groups. An acceptable safety profile is especially important for a treatment designed for chronic use by COPD patients, who tend to be elderly and often have comorbidities, the most important being cardiovascular conditions, lung cancer and osteoporosis [23-25].

Cough immediately following indacaterol inhalation has been reported previously [26, 27], and the observation of cough incidence following inhalation of the study drug (as distinct from the recording of cough as an adverse event) was, therefore, pre-specified in the present study. Cough following inhalation was fairly common, but did not appear troublesome to patients. It did not result in any loss of efficacy (comparison of the change from baseline in trough FEV1 showed similar or 
greater increases in patients who coughed compared with those who did not), nor was it associated with bronchoconstriction or withdrawal from the study.

This and other comparative studies show that indacaterol is a more effective bronchodilator than salmeterol and the other twice-daily $\beta_{2}$-agonist, formoterol [5], and that it may prove to be at least as effective as the once-daily anticholinergic bronchodilator, tiotropium [4]. They also show that indacaterol improved health status and reduced dyspnoea versus placebo and was better than, or at least as effective as, the currently available bronchodilator agents in respect of improving clinical outcomes [4, 5]. The findings of early-morning bronchodilation with sustained reduction in dyspnoea and improved health status are important for the lives of patients with COPD, and suggest that once-daily indacaterol will be a useful additional option for treating this disabling condition.

\section{CLINICAL TRIAL}

This study is registered at ClinicalTrials.gov with clinical trial identifier number NCT00567996.

\section{STATEMENT OF INTEREST}

Statements of interest for all authors can be found at www.erj. ersjournals.com/site/misc/statements.xhtml

\section{ACKNOWLEDGEMENTS}

The authors thank the patients and staff at the participating centres in the study. S. Filcek (Acumed, Tytherington, UK), a professional medical writer funded by Novartis, and D. Young (Novartis, Horsham, UK) assisted in the preparation of the manuscript.

\section{REFERENCES}

1 Buist AS, McBurnie MA, Vollmer WM, et al. International variation in the prevalence of COPD (The BOLD Study): a population-based prevalence study. Lancet 2007; 370: 741-750.

2 Mannino DM, Buist AS. Global burden of COPD: risk factors, prevalence, and future trends. Lancet 2007; 370: 765-773.

3 Global Initiative for Chronic Obstructive Lung Disease. Global Strategy for the Diagnosis, Management, and Prevention of Chronic Obstructive Pulmonary Disease. www.goldcopd.com/ GuidelineItem.asp?intId=1386 Date last accessed: January 17, 2010. Date last updated: 2009.

4 Donohue JF, Fogarty C, Lötvall J, et al. Once-daily bronchodilators for chronic obstructive pulmonary disease: indacaterol versus tiotropium. Am J Respir Crit Care Med 2010; 182: 155-162.

5 Dahl R, Chung KF, Buhl R, et al. Efficacy of a new once-daily LABA, indacaterol, versus the twice-daily LABA, formoterol, in COPD. Thorax 2010; 65: 473-479.

6 Global initiative for chronic obstructive lung disease (GOLD). Global Strategy for the Diagnosis, Management, and Prevention of chronic obstructive pulmonary disease. www.goldcopd.com Date last accessed: January 17, 2010. Date last updated: 2005.

7 Jones PW, Quirk FH, Baveystock CM, et al. A self-complete measure of health status for chronic airflow limitation. The St. George's Respiratory Questionnaire. Am Rev Respir Dis 1992; 145: 1321-1327.
8 Jones PW. St. George's Respiratory Questionnaire: MCID. COPD 2005; 2: 75-79.

9 Mahler DA, Weinberg DH, Wells CK, et al. The measurement of dyspnea. Contents, interobserver agreement, and physiologic correlates of two new clinical indexes. Chest 1984; 85: 751-758.

10 Witek TJ Jr, Mahler DA. Minimal important difference of the transition dyspnoea index in a multinational clinical trial. Eur Respir J 2003; 21: 267-272.

11 Dahl R, Greefhorst LA, Nowak D, et al. Inhaled formoterol dry powder versus ipratropium bromide in chronic obstructive pulmonary disease. Am J Respir Crit Care Med 2001; 164: 778-874.

12 Rossi A, Kristufek P, Levine BE, et al. Comparison of the efficacy, tolerability, and safety of formoterol dry powder and oral, slowrelease theophylline in the treatment of COPD. Chest 2002; 121: 1058-1069.

13 Mahler DA, Donohue JF, Barbee RA, et al. Efficacy of salmeterol xinafoate in the treatment of COPD. Chest 1999; 115: 957-965.

14 Cazzola M, MacNee W, Martinez FJ, et al. Outcomes for COPD pharmacological trials: from lung function to biomarkers. Eur Respir J 2008; 31: 416-469.

15 Donohue JF, van Noord JA, Bateman ED, et al. A 6-month, placebo-controlled study comparing lung function and health status changes in COPD patients treated with tiotropium or salmeterol. Chest 2002; 122: 47-55.

16 Hanania NA, Darken P, Horstman D, et al. The efficacy and safety of fluticasone propionate $(250 \mu \mathrm{g}) /$ salmeterol $(50 \mu \mathrm{g})$ combined in the Diskus inhaler for the treatment of COPD. Chest 2003; 124: 834-843.

17 Hodder R, Kesten S, Menjoge S, et al. Outcomes in COPD patients receiving tiotropium or salmeterol plus treatment with inhaled corticosteroids. Int J Chron Obstruct Pulmon Dis 2007; 2: 157-167.

18 Partridge MR, Karlsson N, Small IR. Patient insight into the impact of chronic obstructive pulmonary disease in the morning: an internet survey. Curr Med Res Opin 2009; 25: 2043-2048.

19 Welte T, Miravitlles M, Hernandez P, et al. Efficacy and tolerability of budesonide/formoterol added to tiotropium in patients with chronic obstructive pulmonary disease. Am J Respir Crit Care Med 2009; 180: 741-750.

20 ZuWallack RL, Mahler DA, Reilly D, et al. Salmeterol plus theophylline combination therapy in the treatment of COPD. Chest 2001; 119: 1661-1670.

21 Calverley P, Pauwels R, Vestbo J, et al. Combined salmeterol and fluticasone in the treatment of chronic obstructive pulmonary disease: a randomised controlled trial. Lancet 2003; 361: 449-456.

22 Celli BR, Cote CG, Marin JM, et al. The body-mass index, airflow obstruction, dyspnea, and exercise capacity index in chronic obstructive pulmonary disease. N Engl J Med 2004; 350: 1005-1012.

23 Sin DD, Anthonisen NR, Soriano JB, et al. Mortality in COPD: role of comorbidities. Eur Respir J 2006; 28: 1245-1257.

24 Barnes PJ, Celli BR. Systemic manifestations and comorbidities of COPD. Eur Respir J 2009; 33: 1165-1185.

25 Huiart L, Ernst P, Suissa S. Cardiovascular morbidity and mortality in COPD. Chest 2005; 128: 2640-2646.

26 Rennard S, Bantje T, Centanni S, et al. A dose-ranging study of indacaterol in obstructive airways disease, with a tiotropium comparison. Respir Med 2008; 102: 1033-1044.

27 Beier J, Chanez P, Martinot JB, et al. Safety, tolerability and efficacy of indacaterol, a novel once-daily $\beta_{2}$-agonist, in patients with COPD: a 28-day randomised, placebo controlled clinical trial. Pulm Pharmacol Ther 2007; 20: 740-749. 